\title{
A avaliação vista sob o aspecto da educação a distância
}

\author{
Maurício Rosa \\ Marcus Vinicius Maltempi
}

\section{Resumo}

Este artigo trata da avaliação como um aspecto bastante relevante para a educação em geral, que também deve ser pensado e discutido frente à Educação a Distância (EAD). Assim, a partir de nossa experiência como professores e tendo por contexto um curso realizado totalmente à distância, analisamos algumas interações ocorridas ao longo do curso, que foi desenvolvido tendo como norte a teoria educacional construcionista. Valemonos também desta teoria para elaborar nossas idéias a respeito do caráter da avaliação frente a uma concepção formativa, em um ambiente de EAD, o qual valorizou todos os tipos de interação. Então, aliamos o Construcionismo' à Avaliação Formativa que visa ao aperfeiçoamento do processo de aprendizagem do aluno em vez de buscar medir o que este aprendeu.

Palavras-chave: Avaliação formativa. Construcionismo. Educação a distância.

\section{Abstract \\ Evaluation from \\ an EAD perspective}

This paper presents the assessment as an aspect, sufficiently important for the education in general, that also it must be thought and be discuss in front of the Distance Education. Thus, from our experience as professors and having for context a course fulfilled totally at distance, we analyzed some interactions that occurred during the course, which was developed having as north the constructionist educational theory. We also used this theory to elaborate our ideas regarding the character of the evaluation front of a formative conception, in an environment of Distance Education, which valued all the types of interaction. Then, we united the

\footnotetext{
1 "[...] é uma teoria educacional (ou de aprendizagem) desenvolvida pelo matemático Seymour Papert, que se baseia, principalmente, na teoria epistemológica desenvolvida por Jean Piaget, a qual procura explicar o que é conhecimento e como ele é desenvolvido pelas pessoas em diferentes momentos de suas vidas" (MALTEMPI, 2005, p. 2).
} 
Constructionism with the Formative Evaluation, which aims to perfect the learning process of the pupil instead of measure what this learned.

Keywords: Formative evaluation. Constructionism. Distance education.

\section{Resumen}

\section{La evaluación bajo el aspecto de la educación a distancia}

Este artículo trata de la evaluación como un aspecto muy destacado en la educación, y que debe ser discutido en el marco de la Educación a Distancia (EaD). Luego, con base en nuestra experiencia como docentes y en el marco de un curso realizado totalmente a distancia, investigamos algunas interacciones ocurridas a lo largo del curso que se desarrolló teniendo en cuenta la teoría educacional Construccionista. Empleamos también esta teoría al elaborar nuestras ideas respecto al carácter de la evaluación frente a una concepción formativa, en un ambiente de EaD, en el que se valoro a todo tipo de interacciones. De hecho, unimos el Construccionismo a la Evaluación Formativa buscando el mejor desarrollo del proceso de aprendizaje en lugar de buscar una medida de aquello que un alumno pueda haber aprendido.

Palabras clave: Evaluación formativa. Construccionismo. Educación a distancia.

\section{Introdução}

Ao realizarmos um curso a distância que apresentou a construção de jogos eletrônicos do tipo RPG ${ }^{2}$ como proposta pedagógica, além de discutir questões relativas à sociedade do conhecimento, a teorias de aprendizagem, entre outras, pudemos verificar que, a partir desse cenário, a avaliação proposta nesse curso apresentou-se de acordo com a concepção de conhecimento $^{3}$ na qual depositamos confiança. Assim, a avaliação sob uma perspectiva construcionista pôde ser evidenciada como um aspecto da Educação a Distância que contribui para a construção do conhecimento do aprendiz em tal contexto.

Verificamos que a avaliação realizada no ambiente de construção de RPGs eletrônicos, assim como, na constituição de conjecturas elaboradas no decorrer das discussões, realizadas de maneira síncrona via chat, a respeito de textos lidos durante o curso, forma parte de um quadro de aspectos da EaD.

Nesse sentido, trabalharemos esse aspecto, nesse contexto, a partir de diferentes teóricos e apresentaremos dados coletados no curso que indicam a avaliação como processo formativo (próprio à Educação). No entanto, faremos inferências à concepção, equivocada em nossa opinião, de avaliação como quantificação, como ideologia de medição de conhecimento, ou seja, como exigência realizada pelo sistema educacional que incita uma atribuição de valores ou conceitos ao

\footnotetext{
${ }^{2}$ RPG -Role Playing Game significa "jogo de interpretação de personagem" ou "jogo de faz-de-conta" e é uma modalidade dentre os jogos que utiliza como base a interpretação e a imaginação dos seus participantes, ou seja, do jogador e do mestre (pessoa responsável em construir a atmosfera do jogo, além de conduzir a história no mesmo) (ROSA, 2004).

${ }^{3}$ A concepção de conhecimento por nós entendida, na verdade, é uma representação da nossa visão de como se dá a aprendizagem em ambientes educacionais. Assim, tal concepção se sustenta no Construcionismo que é uma teoria de aprendizagem que valoriza o processo ativo de construção e reconstrução das estruturas mentais, no qual o aprendiz constrói um produto, desenvolve um projeto (MALTEMPI, 2004; ROSA, 2004).
} 
que o aluno "sabe" ou "aprende". Fato que, a nosso ver, é totalmente subjetivo ${ }^{4}$ e que deve ser visto com um "olhar diferente", em um cenário constituído dentro da perspectiva da Educação a Distância.

Dialogaremos, também, com estudiosos que tratam da teoria de aprendizagem denominada Construcionismo, a qual serviu como pano de fundo para a proposta pedagógica apresentada no decorrer do curso, ou seja, a construção de jogos eletrônicos, assim como, para a constituição do processo avaliativo efetivado no decorrer do curso, realizado completamente à distância.

Entretanto, antes de qualquer coisa, cabe situar o leitor no contexto do curso, apresentando-o, inicialmente, para que possamos a partir desse, evidenciar a avaliação como aspecto da EaD, que se revelou no interior da proposta pedagógica empregada no mesmo.

\section{O curso: Informática e jogos: a tecnologia lúdica aplicada à educação}

$\mathrm{O}$ curso em questão foi realizado no $2^{\circ}$ semestre de 2004. Possuiu uma carga horária de 80 horas, totalmente a distância, desenvolvido na plataforma TelEduc ${ }^{5}$, contando com suas ferramentas de comunicação e interação, síncronas e assíncronas. Além dessa plataforma, foram utilizados, também, os softwares RPG Maker, que possibilita a construção de RPGs eletrônicos e o Ultra VNC, o qual possibilita o controle remoto, a distância e em tempo real, de computadores e os softwares neles instalados.
Visando à divulgação de diferentes alternativas de ensino e aprendizagem, que possibilitem maior interesse, participação e interação dos aprendizes, elaboramos esse curso a distância que adotou uma metodologia de ensino e aprendizagem, utilizando a construção de jogos eletrônicos como contexto pedagógico.

Nesse sentido, o curso possuiu um cronograma cujas idéias norteadoras baseavam-se no Construcionismo, que segundo Maltempi (2004, p. 265):

É tanto uma teoria de aprendizado quanto uma estratégia para educação, que compartilha a idéia construtivista de que o desenvolvimento cognitivo é um processo ativo de construção e reconstrução das estruturas mentais, no qual o conhecimento não pode ser simplesmente transmitido do professor para o aluno. $\bigcirc$ aprendizado deve ser um processo ativo, em que os aprendizes "colocam a mão na massa" (hands-on) no desenvolvimento de projetos, em vez de ficarem sentados atentos à fala do professor.

Tomando tal teoria como base, a ementa apresentou-se da seguinte forma:

1. Sociedade do conhecimento;

1.1 Mudanças na sociedade, mudanças na educação;

$1.2 \bigcirc$ papel do computador;

2. Diferentes usos do computador na educação;

2.1 Construcionismo versus Instrucionismo;

2.2 Aprendizagem por projetos;

2.3 Papel do professor, aluno e comunidade;

\footnotetext{
${ }^{4}$ Entendemos por subjetivo aquilo que é denotado pela própria palavra: "relativo ao sujeito; existente no sujeito; que se passa na consciência; que é próprio de um ou de vários sujeitos e que não é válido para todos" (PRIBERAM, 2005).

5 "[...] ambiente para a criação, participação e administração de cursos na Web" (ROCHA, 2002, p. 197).
} 
3. Ciclo de aprendizagem;

3.1 Explicitação de conhecimento;

4. Prática da abordagem construcionista;

4.1 Nas escolas;

4.2 Nas empresas;

4.3 À distância;

5. Jogo, informática e educação;

5.1 Importância dos jogos na educação;

5.2 Possibilidades e tipos;

5.3 RPG (Role Playing Game);

6. RPG Maker;

6.1 Introdução;

6.2 Construção de jogos; e

6.3 Aplicações.

Seguindo o planejamento do curso a distância, desenvolvemos atividades de modo a propiciar a participação e a construção do conhecimento por parte dos estudantes. Para tanto, colocamos em prática a espiral de aprendizagem que foi parte do conteúdo do curso e que enfatiza a depuração de conhecimentos em trabalhos com projetos (VALENTE, 2002).

Além disso, para uma possível análise dos dados obtidos nesse curso, ampliaremos o entendimento das ações de aprendizagem da espiral, tomando para isso o processo intitulado Turbilhão de Aprendizagem (ROSA, 2004).

Entre as atividades que compuseram o curso temos: a pesquisa de materiais, leituras, apresentação e discussão de textos, redação de resenhas e o desenvolvimento de um projeto que compreendeu a elaboração de um jogo eletrônico do tipo RPG, para fins educativos. Dessa forma, foram solicitados relatórios sobre os encontros síncronos e pré-projetos que eram desenvolvidos no decorrer do curso, os quais eram lidos e reenviados aos autores com sugestões para mudanças e questionamentos referentes ao conteúdo, em consonância com a teoria discutida nos encontros síncronos.

○ jogo foi construído no RPG Maker, software gratuito, disponível para download na Internet e também na página Web do próprio curso 6 , e sua construção foi discutida através de sessões realizadas na ferramenta bate-papo da plataforma TelEduc. No período de desenvolvimento e discussão das propostas do jogo (a partir de 13/ 10/2004), os participantes utilizavam em conjunto com o chat, o software Ultra VNC que permitia a manipulação à distância e em tempo real do software RPG Maker, tanto por parte dos alunos quanto dos formadores. Essas sessões de atendimento foram préagendadas e oferecidas a cada aluno.

Anteriormente à elaboração dos projetos, o chat foi utilizado como recurso para debate dos textos pré-selecionados e, por causa disso, houve a prévia definição dos alunos responsáveis por conduzi-lo, com questões geradoras de discussões, a partir da leitura desses textos. Esses alunos (coordenadores das sessões de discussão dos textos) também utilizaram a ferramenta "bate-papo" como meio de interação anterior às sessões de discussão. Cabe ressaltar que nessas interações não havia a presença (virtual) de qualquer formador.

fórum, por sua vez, foi utilizado também para discutir os projetos e questões provenientes dos debates ocorridos na ferramenta "bate-papo" (além de questões ligadas ao

${ }^{6}$ Download disponível no decorrer do curso em: < http://black.rc.unesp.br/marcus/curso >. 
RPG Maker, RPG etc.). Já o e-mail possuiu como função, a troca de mensagens entre professor/aluno e aluno/aluno, a fim de elucidar dúvidas, aprofundar temas e dinamizar o trabalho em grupo. Ambos (fórum e e-mail) constituíram ferramentas assíncronas de interação no curso promovido.

O número total de participantes do curso fixou-se em 15, sendo 11 alunos matriculados, o coordenador, o formador e dois alunos de iniciação científica (convidados a participar do curso como colaboradores). Dentro dessas perspectivas, os participantes representavam quatro Estados do Brasil e diferentes cidades dos mesmos.

\section{Aspectos teóricos}

Considerando que o curso realizado por nós, totalmente à distância, possuía como um dos seus objetivos a formação dos participantes no que tange a prática educativa, em termos de construção de jogos eletrônicos, entendemos que parte dessa formação se faz também a partir da inclusão digital desse profissional. Assim, não diferente de outros, o professor, ou o futuro professor, insere-se na sociedade do conhecimento, a qual se vincula a um mundo globalizado em que as Tecnologias da Comunicação e Informação (TIC) possuem um papel de destaque.

Da mesma forma, nesse inserir-se no mundo tecnológico é imprescindível à nossa formação contínua que façamos uma reflexão sobre como se caracteriza o processo avaliativo que tem nas TIC, no caso, na EaD, um aporte diferenciado em relação ao ensino tradicional. Assim, podemos questionar isso quando percebemos que as TIC possibilitam diferentes formas de pensar, em relação à linearidade de raciocínio defendida no ensino tradicional (MIZUKAMI, 1986), pois se- gundo Borba e Penteado (2001, p. 46), [...] devemos entender a informática. Ela é uma nova extensão de memória, com diferenças qualitativas em relação às outras tecnologias da inteligência e permite que a linearidade de raciocínios seja desafiada por modos de pensar, baseados na simulação, na experimentação, e em uma "nova linguagem" que envolve escrita, oralidade, imagens e comunicação instantânea.

As TIC permitem ainda a formação de uma rede de conhecimentos, que interligados em diversos sentidos, unem-se em uma estrutura que propicia a expansão da criatividade, da imaginação, da memória e conseqüentemente dos sentidos (ROSA, 2004).

Da mesma forma, todo esse processo na EaD tem acontecido, conforme Borba (2004, p. 297), "[...] à medida que novas interfaces para a Internet têm surgido. Em particular, a www aproximou bem mais as tecnologias informáticas do usuário por ter eliminado passos intermediários que teriam que ser dados para que a comunicação se efetuasse". Além disso, as transformações da informática trouxeram modificações às noções de tempo e espaço por nós vividos. Kenski (2003, p. 32), corrobora essa idéia quando afirma que: "O tempo, o espaço, a memória, a história, a noção de progresso, a realidade, a virtualidade e a ficção são algumas das muitas categorias que são consideradas em novas concepções baseadas nos impactos que, na atualidade, as tecnologias eletrônicas têm em nossas vidas".

Nesse sentido, a avaliação que acontece em cursos realizados à distância também vem sofrendo transformações, principalmente, quanto à concepção de avaliação e ca- 
minha para outras, ainda mais expressivas, que contam com a colaboração do advento das TIC, como por exemplo, o uso de Inteligência Artificial nesse processo.

No caso do curso "Informática e jogos: a tecnologia lúdica aplicada à educação", abordado nesse artigo, procedemos a concepção de avaliação formativa ${ }^{7}$ a partir das interações realizadas nos ambientes síncronos e assíncronos, oferecidos no TelEduc. Optamos por tal concepção, por ser mais coerente com a abordagem educacional utilizada no curso, a qual foca muito mais o processo do que o produto, visando muito mais a aperfeiçoar do que julgar (ou medir) o que está sendo aprendido (PERRENOUD, 1999).

Dessa forma, nos concentramos na qualidade da participação dos alunos, nas intervenções feitas por eles via "batepapo" e "fórum", ao longo das discussões motivadas pelos textos e pelo desenvolvimento de seus projetos na forma de um jogo de RPG eletrônico. Tal processo de avaliação é complexo e despende bastante tempo, pois implica em entender como o conhecimento sobre o conteúdo trabalhado está sendo construído pelo aprendiz, a fim de identificar as falhas e oportunidades para a intervenção do educador. Requer, portanto, diálogos constantes e leituras de pré-projetos, a fim de que feedbacks possam ser trocados, o que caracteriza um grande volume de texto a ser lido pelos professores.
Por outro lado, se pensarmos em cursos a distância que façam uso de outras mídias, além do texto, por exemplo, videoconferência, a quantidade de dados que precisa ser analisada aumenta, impactando mais ainda no tempo e esforço que o professor deve despender a fim de realizar a avaliação formativa. Tal fato indica a premente necessidade por ferramentas computacionais desenvolvidas especificamente para auxiliar esse processo, as quais atualmente são raras, pois geralmente restringem-se somente à análise de dados quantitativos. A idéia é evitar a sobrecarga de informação ao docente, através de mecanismos automáticos que filtrem o essencial, do irrelevante, utilizando para isso, agentes inteligentes ${ }^{8}$, por exemplo (JAQUES et al., 2002). Dessa forma, o professor teria mais condições de dar um feedback adequado e pertinente ao aluno, favorecendo a construção de conhecimentos por este.

Com relação a textos, essa filtragem é bastante factível com o uso de agentes de interface 9 (MAES, 1994; BALDASSIN; GUILHERME; MALTEMPI, 2002). Contudo, se pensarmos em vídeo e em realidade virtual, por exemplo, a complexidade aumenta enormemente. No caso do vídeo, por exemplo, pode ser interessante que certos momentos sejam automaticamente registrados para que o professor os analise, evitando, assim, assisti-lo totalmente. $O$ mesmo pode ser pensado no caso da

\footnotetext{
7 "Proponho considerar como "formativa" toda prática de avaliação continua que pretenda contribuir para melhorar as aprendizagens em curso, qualquer que seja o quadro e qualquer que seja a extensão concreta da diferenciação do ensino" (PERRENOUD, 1999, p. 78).

${ }^{8}$ Um agente é qualquer coisa que tenha a capacidade de perceber e agir sobre o ambiente a sua volta (RUSSEL; NORVIG, 1995). Um agente inteligente refere-se a um software agente que exibe alguma forma de inteligência artificial.

${ }^{9}$ Os agentes de interface têm como principais características a capacidade de ser autônomo e de aprender com o ambiente externo, objetivando a realização de tarefas para os seus usuários.
} 
Realidade Virtual, quando alunos interagem em cavernas digitais ${ }^{10}$. Tais momentos seriam filtrados com base em requisitos estabelecidos pelo professor.

Dessa forma, e embora nosso curso não tenha usado vídeo ou Realidade Virtual, queremos chamar a atenção sobre os novos desafios que se apresentarão àqueles que buscam fazer uma avaliação formativa num ambiente de EaD. Tais desafios geram demandas à comunidade de engenheiros de software dispostos a desenvolver tecnologias que auxiliem o professor nessa tarefa tal discussão surgiu em uma das sessões de "bate-papo" do curso, conforme será apresentado na próxima seção deste artigo.

Em nosso curso, então, nos propusemos inserir na avaliação formativa adotada, a própria concepção de conhecimento que discutimos no curso e que acreditamos ser de grande importância, aquela que está consubstanciada no Construcionismo. Logo, acreditamos que a construção do conhecimento está diretamente ligada ao fazer, à ação de projetar. Nesse sentido, dentro dessa proposta, tomando como base as idéias de Papert, Maltempi (2004, p. 265) afirma que $O$ "[...] aprendizado deve ser um processo ativo, no qual os alunos 'colocam a mão na massa' (hands-on) no desenvolvimento de projetos, em vez de ficarem sentados atentos à fala do professor".

Entretanto, só colocar "a mão na massa" não adianta, pois essa atividade pode provocar, muitas vezes, ações repetitivas que são caracterizadas como head-out, quando o aluno não se envolve com as mes- mas, pois os objetivos e as resoluções são dados por terceiros. ${ }^{11}$

Dando continuidade a essa idéia, Maltempi (2004, p. 265) afirma que, A abordagem construcionista vai além de atividades hands-on ao deixar para o aluno mais controle sobre a definição e resolução de problemas. A idéia é criar um ambiente no qual o aluno esteja conscientemente engajado em construir um artefato público e de interesse pessoal (head-in). Portanto, ao conceito de que se aprende melhor fazendo, o Construcionismo acrescenta: e melhor ainda quando se gosta, pensa e conversa sobre o que se faz.

Nesse sentido, a troca de idéias, com feedbacks constantes, predominantemente, vincula-se ao processo avaliativo formativo. Pois, entendemos que ao se inserir nesse processo de grande movimento de idéias, no qual há um grande número de interações entre aluno/aluno, aluno/professor e aluno/mídias, o participante torna-se agente de construção do seu próprio conhecimento e, dessa forma, não é o conhecimento que devemos avaliar, mas a qualidade de suas manifestações. Ou seja, segundo Hoffmann (1996, p. 20), "a avaliação na perspectiva de construção do conhecimento, parte de duas premissas básicas: confiança na possibilidade dos educandos construírem suas próprias verdades e valorização de suas manifestações e interesses".

Entretanto, ao avaliar as interações, o pensar e, principalmente, a construção do conhecimento, faz-se um processo de grande subje-

\footnotetext{
10 Uma caverna digital é um complexo sistema de Realidade Virtual que permite ao usuário adentrar em um mundo tridimensional totalmente simulado por computadores.

11 MALTEMPI, 2004.
} 
tividade, quando queremos atribuir valores quantitativos a esses aspectos. Fato que questiona o próprio sentido e validade da avaliação no que se refere a determinar ou verificar, tendo por base uma escala fixa, a extensão, medida, ou grandeza dos processos cognitivos. Segundo D’Ambrósio (2003, p.78),

[...] avaliação deve ser uma orientação para o professor na condução de sua prática docente e jamais um instrumento para reprovar ou reter alunos na construção de seus esquemas de conhecimento teórico e prático. Selecionar, classificar, filtrar, reprovar e aprovar indivíduos para isto ou aquilo não são missão de educador.

Nesse sentido, acreditamos que comensurar, ou mesmo, ser a medida do que o outro aprendeu, não é uma ação exeqüível e nem que caiba ao professor. No entanto, sabemos que o sistema educacional exige essa comensurabilidade. Para contribuir com o esclarecimento desse embate, tentamos pensar nas possibilidades que temos, a partir da avaliação formativa relacionada à nossa concepção de conhecimento, para mudar o paradigma quantificativo, ou pelo menos, torná-lo mais formativo possível, principalmente, em ambientes de EaD. Pois, da mesma forma,

Nos cursos à distância também existe essa

busca por métodos de avaliação online que possibilitem a avaliação formativa do aluno, baseada no acompanhamento e orientação da participação destes no desenvolvimento de tarefas individuais ou em grupo. No contexto da Educação a Distância (EaD) este novo paradigma de avaliação tem relevância ainda maior por possibilitar a percepção do comportamento do aluno e favorecer a identificação de problemas (ROCHA, 2002, p. 146). $\bigcirc$ Construcionismo, então, interliga-se à perspectiva da avaliação formativa a partir de ações de aprendizagem que favorecem a construção do conhecimento (VALENTE, 1993, 1999, 2002; MALTEMPI, 2000, 2004; ROSA, 2004). As ações são vistas, segundo Rosa (2004), em consonância com uma estrutura denominada Turbilhão ${ }^{12}$ de Aprendizagem. Os processos de descrição/ expressão, execução compartilhada, reflexão/discussão e depuração compartilhada, encontrados no Turbilhão, possibilitam a convergência de idéias apresentadas sobre a questão da avaliação formativa.

A "descrição/expressão", então, é uma ação que sempre considera e necessita de um meio, para que as idéias do aprendiz sejam relatadas. Porém, essa ação considera como meio de expressão não só os materiais, mas também os não materiais, tomando a oralidade como um dos mais importantes. No caso da EaD, essa ação acontece por meio da escrita e se revela de grande valia, por possibilitar que as idéias dos participantes sejam armazenadas, contribuindo para o processo avaliativo.

A "reflexão/discussão" é uma ação encontrada no Turbilhão, que permite a construção de significados em conjunto, da mesma forma que o reconhecimento do pensar do outro. Fato que admitimos ser de muita importância, tanto para a construção do conhecimento individual quanto coletivo, pois, contempla significativamente a discussão proporcionada pelo embate de idéias que, muitas vezes, terminam por fundiremse mesmo antes que qualquer ação seja executada. Percebemos que, "Nessa dimensão,

\footnotetext{
12 "Turbilhão é um vocábulo que representa um movimento forte e giratório, voragem, vórtice, no qual o movimento não possui um único sentido, mas variadas situações e ações ocorrendo ao mesmo tempo, sem que aconteça uma ordem muito explícita" (ROSA, 2005, p. 109).
} 
avaliar é dinamizar oportunidades de açãoreflexão, num acompanhamento permanente do professor, que incitará o aluno a novas questões a partir de respostas formuladas" (HOFFMANN, 1996, p. 20).

Logo, a reflexão/discussão frente a problemas apresentados no decorrer da ação educativa, faz com que apreciemos a qualidade de respostas e entendimento das questões por parte do aprendiz, seja a partir de uma perspectiva empírica desse, seja sob uma análise teórica à luz de textos adotados.

Em relação à ação de "depuração", como ela não ocorre de maneira exclusivamente seqüencial, na construção de RPGs eletrônicos, pois não necessariamente aplica-se imediatamente sobre a questão principal de investigação, assim como, por poder não ser efetivamente a questão gerada pelo aprendiz que a depura, mas por outrem, chamamos essa ação, dentro do Turbilhão de Aprendizagem, de "depuração compartilhada".

Dessa forma, muitas vezes, no processo de depuração compartilhada, dos possíveis "erros" conceituais estabelecidos, há um retorno, um feedback, por parte do mediador frente à teoria estabelecida, de forma que ocorra uma negociação de significados até que se encontre uma satisfação comum entre os participantes da reflexão/discussão.

Nesse sentido, percebemos nessa ação (depuração compartilhada) uma possível aproximação do que o sistema educacional exige quanto avaliação (equacionar formação com prazos e relacionar o avaliar a uma "linha de corte", que represente a aprovação do aprendiz ou o antônimo disso) com nossa concepção do avaliar como formação. Entendemos que não po- demos ficar exercendo as ações de aprendizagem do Turbilhão, em relação a um tópico, por tempo integral, uma vez que, o sistema educacional exige do professor o cumprimento de prazos. Da mesma forma, entendemos que a "linha de corte" exigida pelo sistema não é tarefa do educador. No entanto, queremos contribuir com esse embate ao sugerir que a avaliação formativa do aprendiz, frente ao entendimento de um tópico qualquer, seja finalizada quando o processo de depuração compartilhada se der em relação a um determinado conceito, pois se a depuração não ocorrer, ou não houve o que ser depurado ou o processo ainda não chegou ao fim.

Assim, acreditamos que a formação do estudante será reconhecida como centro dos processos de ensino e de aprendizagem no contexto educacional, retirando da quantificação do saber o grande valor que a esse é atribuído. A formação é dada a partir do reconhecimento das ações de aprendizagem que emitem, cada qual, subsídios que contribuem para o processo de avaliação formativa.

As ações de aprendizagem reflexão/discussão e depuração compartilhada entrelaçam-se, então, com outra já denominada como descrição/expressão de idéias que, no caso do uso da plataforma TelEduc, são registradas, armazenadas no próprio ambiente, o que possibilita o retorno, a releitura do que foi expressado como produto da ação cognitiva.

A "execução compartilhada", por sua vez, se manifesta na execução das idéias previamente articuladas, principalmente no ato de projetar o produto final, seja esse o jogo eletrônico ou outro produto de interesse pessoal, e isso faz com que, possivelmente, outras 
ações de aprendizagem sejam desencadeadas, colaborando para o processo cognitivo. Assim, no Turbilhão a execução é realizada por um conjunto de mídias. No caso da construção de RPGs eletrônicos, os designers, em diversos momentos após refletirem sobre as idéias que são traduzidas ao jogo, executam as ações refletidas no papel, muitas vezes, através de desenhos, ou mesmo, rabiscos feitos nos mapas que utilizam, para somente após isso construírem o jogo.

Dessa forma, cabe ao professor promover a avaliação formativa de maneira que esta participe do processo cognitivo estabelecido a partir das ações de aprendizagem, de forma a estabelecer um grau de satisfação com os significados negociados durante a ação educativa. Logo,

Do ponto de vista dos efeitos da avaliação para o aluno, o mais importante é que ele tome consciência de seu progresso. Não conhecer um determinado assunto, seja por falta de interesse, seja por falta de capacidade é muito difícil de se definir e como educadores não nos cabe reprovar. [...] Selecionar ou filtrar cidadãos para tarefas específicas não é educação (D'AMBRÓSIO, 2003, p. 77).

Assim, devemos utilizar novos mecanismos de informação e comunicação, que na maioria das vezes são de interesse geral, como aliados ao aprendizado. Segundo Martins (2003, p. 92), "as novas tecnologias da comunicação e da informação apontam novas dimensões, que permitem estruturar paisagens educativas mais ricas, variadas e complexas, possibilitando, por exemplo, 'incluir o mundo na aula' e a 'aula no mundo'".
A relação biunívoca aula-mundo na perspectiva da avaliação formativa, frente às ações de aprendizagem inerentes ao Construcionismo, se mostra como o crescer cognitivamente, como o aprender a aprender, como o avaliar qualitativamente tendo por objetivo a negociação de significados, a qual visa à construção do conhecimento.

\section{Episódios destacados no curso}

De acordo com os aspectos teóricos abordados, destacamos, nesse momento, recortes retirados do curso - Informática e Jogos: a tecnologia lúdica aplicada à educação - o qual revela o processo avaliativo em transformação frente à concepção de comensurabilidade do saber. Concepção vista como aspecto subjetivo, presente em diferentes ambientes educacionais, e discutida no ambiente de aprendizagem que constituímos nesse curso, realizado totalmente a distância.

Apresentamos eventos que são recortes ${ }^{13}$ da aula do dia 15 de setembro de 2004, a qual teve como um dos temas a Educação a Distância e, conseqüentemente, a avaliação frente a essa modalidade de ensino. Essa aula, via chat, utilizou como uma das bibliografias a serem discutidas, o texto de Oliveira (2002). Nessa perspectiva, apresentaremos quatro eventos que discutem questões ligadas à avaliação na Educação a Distância e, nesse sentido, procuraremos esclarecer como avaliar as interações estabelecidas frente ao próprio fazer de um curso a distância. Certamente, esse processo

\footnotetext{
${ }^{13}$ Os recortes escolhidos foram organizados de forma temporal e a partir da discussão proponente, ou seja, algumas falas referentes à outra temática, que apareciam entre as falas direcionadas ao assunto do episódio em questão, foram retiradas ou transportadas para o episódio relacionado ao conteúdo da própria fala. Além disso, apresentaremos somente as iniciais dos nomes dos participantes a fim de preservar suas identidades e indicamos por FMM e FMR os momentos em que os formadores do curso se expressam.
} 
avaliativo estará permeado por nossa concepção de conhecimento que identifica o Construcionismo como base teórica.

Assunto da Sessão ${ }^{14}$ : Sessão de Texto 4 Início: 15/09/2004, às 18:49:05h

Fim: 15/09/2004, às $21: 23: 50 h$

\section{Episódio 1: Como avaliar, já que há uma grande quantidade de dados?}

Esse episódio apresenta uma discussão sobre a dificuldade em avaliar o processo de construção de conhecimento em um curso a distância, uma vez que, em ambientes como o TelEduc, no qual todas as falas ficam registradas (armazenadas), a quantidade de dados a serem lidos e discutidos é muito grande. Em torno dessa questão, podemos perceber que há um alto grau de questionamentos e algumas supostas respostas.

(20:4 1:07) Sh fala para FMM: Eu acho que os professores na EaD têm muitos recursos em avaliar os alunos. Como dito no texto onde o programa pode armazenar muitas informações sobre o que o aluno está fazendo ou não... (20:4 1:33) Fer fala para FMM: Como poderíamos ter dados satisfatórios com avaliação em EaD?

(20:42:15) FMM fala para Sh: Mas também tem MUITA informação para esmiuçar... e-mails, fóruns, chats, ......

(20:42:41) Lu fala para FMM: É possível perceber o Ciclo (espiral) analisando os dados armazenados em um software que registra a interação do usuário? Quais seriam as características principais ou tipos de informações que deveríamos ten- tar armazenar para verificar isso? (20:42:49) FMM fala para Todos: Como lidar com a sobrecarga de informação? (20:43:07) Sh fala para FMM: é verdade... (20:43:22) Ro fala para FMM: isso é um grande problema, haja tutores EAD (20:43:58) FMR fala para Lu: O Lu colocou no fórum o seguinte: $O$ texto da Lucila Maria P. de Oliveira, fala sobre o "mapeamento do percurso cognitivo de cada aluno em especial". Não seria isso suficiente para avaliar o aluno? Acho que sim, e com sua pergunta respondo à última colocação feita por você. (20:44:08) FMM fala para Todos: Creio que sim, mas o problema é o excesso de informação inútil que vai estar "escondendo" as que são úteis para o processo avaliativo

(20:44:10) Sh fala para FMM: Como ter todas estas informações e poder manipulá-las de maneira que seja feita uma boa avaliação???

(20:44:50) Ro fala para FMM: O próprio TelEduc já tem algum tratamento destas informações, não tem? Podem explicar como funciona?

No decorrer desse episódio, podemos perceber a discussão de algumas questões referentes à avaliação em cursos a distância. Entre elas, as questões da quantidade de dados, ou seja, a grande quantidade de informação que fica registrada na própria plataforma, que é usada no curso a distância, e a de como fazer a avaliação desse material se destacam.

Dessa forma, nos propusemos a responder às questões frente aos aspectos teóricos aqui levantados e a nossa própria experiên-

\footnotetext{
${ }^{14}$ Como o foco desse artigo não está na linguagem adotada em ambientes educacionais a distância, tratamos de corrigir as expressões utilizadas no chat, como a troca de todos os "vc" pela a palavra correspondente "você", assim como, todo e qualquer erro ortográfico decorrente da digitação.
} 
cia, como avaliadores dos participantes do curso em questão. Nesse sentido, acabamos por avaliar as interações desses, registradas no ambiente TelEduc e que, não por menos, se traduzem em grande quantidade de dados.

processo avaliativo formativo, frente à concepção do Construcionismo, nos mostra que a reflexão/discussão é um processo de grande valia na formação. Refletir e discutir sobre determinado assunto faz com que a negociação de significados frente ao tema em questão, se estabeleça. Nessa perspectiva, a reflexão sobre a quantidade de dados em um curso a distância se torna objeto a ser considerado em relação à idéia de avaliação e isso é perceptível no ambiente utilizado, pois a descrição/expressão de idéias, as quais ficam registradas na plataforma, nos permitem fazer questionamentos a partir das concepções de outrem.

Tal fato pode ser visto quando Lu pergunta a FMM como se traduz a espiral ${ }^{15}$ de aprendizagem (termo que adota as ações de aprendizagem dadas como descriçãoexecução-reflexão-depuração) em dados recorrentes de um curso a distância e como avaliá-los de forma que se enquadrem nas respectivas ações de aprendizagem. Da mesma forma, nossa avaliação formativa relativa ao participante Lu se dá quando ao responder a questão levantada por esse participante, FMR devolve uma pergunta, levantando um problema e citando um comentário inserido no fórum pelo próprio Lu. Fato que apresenta a indicação de uma reflexão/discussão sobre algo descrito/expressado no fórum, possibilitando um crescimento de ambos, frente ao que estava sendo discutido no decorrer do chat.
Em conseqüência, FMR acompanha e orienta a participação de Lu, no desenvolvimento da tarefa proposta, conforme é indicado por Rocha (2002) e, assim, revela seu posicionamento como indício de uma negociação de significados frente ao questionamento inicial expressado.

\section{Episódio 2: Avaliação formativa na EaD}

Esse episódio apresenta uma discussão relativa à avaliação formativa. Desse modo, é questionado o que significa tal expressão. Dentro dessa perspectiva, as informações que se traduzem em resposta partem de diferentes fontes, seja dos formadores, ou dos cursistas.

(20:45:13) Pri fala para Fer: Acho que ao averiguar as participações do aluno, como interação tanto assíncrona quanto síncrona, iá é uma forma de avaliar... (20:45:15) Lu fala para FMR: Que tipo de interação é importante armazenarmos? (20:46:21) Al fala para FMM: Não sei se posso mas sugiro os autores LIBÂNEO e LUCKESI, pois tratam muito bem a questão da avaliação e podem contribuir muito para a concepção da Avaliação na Educação a distância. (20:46:23) FMM fala para Todos: Pessoal, só queria esclarecer que estou pensando em avaliação formativa (20:47:03) Sh fala para FMM: o que é avaliação formativa?

(20:47:07) La fala para FMM: Acho que se for selecionar vai ficar incompleta a avaliação, mas concordo que é muita informação...

(20:47:28) FMM fala para Ro: O TelEduc tem algumas ferramentas que auxiliam na interpretação do qualitativo, mas não na linha a que me referia

\footnotetext{
${ }^{15}$ Mais informações, ver Valente (2002).
} 
(20:48:20) Al fala para FMM: vou pesquisar alguns links sobre os autores e colocar no fórum.

(20:48:24) FMM fala para Sh: É uma avaliação do processo, não pontual (como uma prova - que é chamada de avaliação somativa).

(20:48:55) FMM fala para La: Não fica incompleto, pois a maior parte dos registros não serve para muita coisa

(20:49:43) FMR fala para Lu: todas as interações, a avaliação formativa, como disse o FMM, tanto a distância quanto no presencial terá um excesso de dados. A diferença é que os dados na EAD ficam armazenados e você, caso não marque na hora, o que você achou importante terá muito material para analisar. Na presencial, o que você achou importante deve ser registrado no momento do ocorrido, porque caso contrário tem grande probabilidade de se perder.

- conceito de avaliação formativa é interrogado e, nesse sentido, a descrição/ expressão desse conceito é revelado por FMM, de acordo com o que diz Perrenoud (1999), quando garante ser típico desse tipo de avaliação focar muito mais o processo do que o produto, visando muito mais a aperfeiçoar do que a medir o que está sendo aprendido.

No sentido de aperfeiçoamento, podemos avaliar tal processo ocorrendo com o participante $\mathrm{Al}$ que revela dois autores que tratam do assunto em questão, descrevendo uma especificidade de conhecimento sobre o tema (reconhece autores que escrevem sobre avaliação), ou mesmo, uma leitura prévia a respeito. Além disso, posteriormente, revela que estaria procurando outros sites relacionados aos autores por ele citados, dando margem para que se perceba um interesse em aprofundar seu conhecimento e compartilhá-lo com os demais. Tal fato, também, nos remete à abordagem construcionista que defende a idéia de ir além de atividades hands-on, ao deixar para o aluno mais controle sobre a definição e resolução de problemas. A idéia é criar um ambiente no qual o aluno esteja conscientemente engajado, fato percebido pelas atitudes de $\mathrm{Al}$.

\section{Episódio 3: Possibilidades futurísticas envolvendo Inteligência Artificial}

$\bigcirc$ presente episódio traz a tona questões relacionadas com as TIC. Nesse sentido, são levantadas questões referentes à Inteligência Artificial como suporte ao processo avaliativo. Da mesma forma, questionados os aspectos da plataforma TelEduc que possivelmente auxiliariam em tal processo.

(20:51:46) Lu fala para FMR: É mesmo [...]. Você acha que é possível desenvolver softwares com inteligência computacional capaz de avaliar essas informações de modo coerente com a realidade, como poderia fazer um tutor que analisasse as informações detalhadamente? [...]. Essa pergunta serve para todos...

(20:52:44) Ro fala para Lu: Alguns sistemas estão trabalhando pra isto, o AulaNet tem alguma coisa desenvolvida e acredito que o TelEduc também (20:52:49) FMM fala para Lu: Sim. Tem pessoas ligadas ao TelEduc que estão trabalhando com Agentes Inteligentes para filtrar essas informações.

(20:53:00) La fala para Lu: Acho que fica muito complicado [...] como os softwares vão julgar o que é interessante ou não...? 
(20:53:06) FMR fala para Lu: acho que sim, é claro que o software não terá o potencial de análise que o ser humano tem, mas talvez com a evolução da tecnologia isso possa ser cada vez mais amenizado. (20:53:29) FMM fala para La: Eles vão aprender com os professores o que é ou não interessante [...].

(20:53:50) FMR fala para Lu: Por enquanto essa avaliação é voltada muito para o quantitativo

(20:55:07) FMM fala para La: Tem um tal de Agente de Interface que é como uma secretária recém contratada que passa um tempo vendo como o chefe trabalha pra depois tentar reproduzir (20:55:29) Lu fala para Todos: Legal [...]. Eu acho muito bonito o trabalho de "agentes inteligentes", ou melhor, a mente que o projetou.

(20:55:37) La fala para FMM: Nossa que interessante...

A necessidade por ferramentas computacionais desenvolvidas especificamente para auxiliar o processo avaliativo, as quais atualmente são raras, pois geralmente restringem-se somente a análise de dados quantitativos, é fato possível de se observar na reflexão/discussão transcrita nos diálogos do curso. Nesse sentido, é perceptível na fala (escrita) dos participantes que a idéia é evitar a sobrecarga de informação ao docente, através de mecanismos automáticos que filtrem o essencial do irrelevante, utilizando para isso, agentes inteligentes (JAQUES et al., 2002). Isso pode ser percebido nas falas de Ro e FMM quando direcionam a idéia de sistemas inteligentes, os quais parecem pertencer a um futuro próximo a nossa realidade.

Tais agentes, os quais já estão sendo utilizados para auxiliar a avaliação, em casos específicos, em cursos determinados, com relação a textos, começam a possuir uma filtragem que é bastante factível com o uso de agentes de interface (MAES, 1994; BALDASSIN et al., 2002). Nesse sentido, mesmo não possuindo tais recursos para auxiliar na avaliação formativa dos participantes do curso em questão, tomamos: os questionamentos de Lu como fator determinante de reflexão; o pronunciamento de Ro como indício de negociação de significado, já que ela compartilha seu conhecimento a respeito do assunto; e a manifestação de La como de interesse, a respeito do que está sendo discutido.

Assim, formam-se diferentes e importantes manifestações para o processo de avaliação formativa, pois permitem a construção do conhecimento do grupo, a partir das ações de aprendizagem. Por exemplo, "reflexão/discussão" no caso de Lu, descrição/expressão em relação à Ro e execução compartilhada de idéias, fato retratado pela expressão de interesse de La, que recebe o feedback da reflexão/discussão promovida por outros.

No entanto, mesmo que pareça, nesta análise, que tais ações são estanques, tomamos todo o processo como um constante movimento entre as ações representadas, formando assim o que chamamos de Turbilhão de Aprendizagem (ROSA, 2004).

\section{Episódio 4: Avaliar: o quê, como e quem?}

Neste episódio são discutidas diversas ações que permeiam o processo avaliativo. Primeiramente, há uma reflexão sobre o que deve ser avaliado. Entende-se que a participação, ou seja, a interação do aluno é o que realmente possui importância. 
Em seguida, a reflexão parte para como avaliar. Nesse sentido, o instrumento avaliativo é questionado e, dessa maneira, a prova como instrumento de atribuição de valores toma o centro da reflexão. Da mesma forma e não como elemento derradeiro da reflexão, quem se deve avaliar toma posse em lugar de destaque no cabedal discursivo. "A quem se está avaliando" é o questionamento presente, pois o anonimato na Internet, no caso, na EaD é fato que deve ser considerado. Assim, percebe-se que o processo avaliativo enquanto comensurar conhecimento está a enriquecer-se, cada vez mais, de subjetividade.

(20:45: 13) Pri fala para Fer: Acho que ao averiguar as participações do aluno, como interação tanto assíncrona quanto síncrona, já é uma forma de avaliar... (20:46:34) Fer fala para Todos: Concordo Pri. Mas, a meu ver, penso nas provas nas aulas presenciais. Como isso poderia ser administrado no TelEduc, por exemplo?

(20:48:01) Pri fala para Fer: Pois é, à distância não sabemos quem realmente está sendo avaliado certo? Pois a pessoa pode não estar sozinha...

(20:48:35) La fala para Fer: é o que ou colocou no fórum [...]

(20:48:47) Fer fala para FMM: FMM, como eu posso utilizar o TelEduc para fazer uma boa avaliação dos alunos na matéria de Cálculo?

(20:49:08) Ro fala para Todos: agora sejamos honestos, vocês nunca viram alunos que fazem provas por outros em cursos presenciais? Ou que trocam de folhas de prova na mesma sala? A questão é o que tratamos como avaliação, somente provas?

(20:49:54) Fer fala para Ro: concordo com você

(20:49:55) Pri fala para Ro: Concordo com você Ro [...]
(20:50: 14) FMM fala para Todos: Se pensarmos em avaliação formativa, na qual acompanho o aluno durante todo o curso, essa história de um se passar por outro fica [...] minimizada, pois seria [passível de ser] detectável (20:50:49) Pri fala para Ro: Pois é, mas a maioria das avaliações, está baseada em provas, eu vejo pela minha faculdade mesmo [...]. Ou melhor, acho que todas as universidades [...]

(20:51:27) La fala para FMM: Como assim avaliação formativa?

(20:51:42) Ro fala para Pri: e mesmo nos colégios, mas quem garante que em um trabalho individual ou em grupo houve a participação do(s) aluno(s). A avaliação deve ser ao longo do processo

O chat estabeleceu discussões sobre o que avaliar, como avaliar e quem avaliar, estando em um curso a distância. Nesse sentido, questões que estão em consonância com a avaliação formativa foram levantadas. Um exemplo disso aparece na descrição/expressão da participante Pri, quando essa atribui à participação dos alunos (interações tanto síncronas como assíncronas) valor significativo, uma vez que ela toma tais ações como objetos a serem avaliados e permite a reflexão sobre "o quê" deve ser avaliado.

Implicitamente, podemos sugerir que o avaliar a participação (expressão utilizada por Pri) interliga-se ao contribuir com a formação do estudante, no que tange as suas contribuições nas discussões, manifestações relativas às leituras realizadas e significados descritos/expressados, refletidos/discutidos, executados e, muitas vezes, depurados de maneira compartilhada, ou seja, o "como" avaliar as interações tornase uma ação coerente com a abordagem educacional utilizada, a qual foca muito mais o 
processo do que o produto, visando muito mais a aperfeiçoar do que a julgar o que está sendo aprendido (PERRENOUD, 1999).

Nessa perspectiva, também avaliamos o processo do participante Fer, entrecruzando a teoria sobre avaliação formativa com nossa concepção de conhecimento. Assim, percebemos que esse participante evolui em sua formação quando descreve/ expressa, inicialmente, sua idéia da avaliação estar vinculada ao instrumento avaliativo específico que é a prova e, em seguida, passar para a reflexão/discussão a respeito de como isso se daria na EaD, pois preocupa-se com "quem" seria avaliado, já que a EaD permite o anonimato.

Conseqüentemente, Fer continua sua indagação remetendo-se a disciplina de Cálculo Diferencial e Integral, a qual, na maioria das vezes, possui a prova como instrumento avaliativo e sessões presenciais de avaliação, com data e hora marcadas. No entanto, Fer consegue, em contraponto, uma boa argumentação a respeito do assunto, iniciada por sua colega Ro que "mergulha" na reflexão/discussão a respeito do instrumento avaliativo prova.

Ro descreve/expressa sua idéia sobre a incompatibilidade de entendermos, ou até mesmo, tornarmos a prova um sinônimo de avaliação. Nesse sentido, a EaD está desvinculada desse acontecimento, pois como já manifestado antes, a dificuldade de se saber "quem" faz a prova (no caso da EaD, se seria realmente o aluno participante do curso ou não, ou mesmo, como fazer uma prova garantindo que o participante não consulte qualquer obra de referência) está presente nesse ambiente. Da mesma forma, é importante desvincular o significado de prova do de avaliação, pois se o fizermos na perspectiva de avaliação formativa, segundo a própria fala de FMM, perceberemos que com esta, que se volta para o processo, a troca de sujeito em cursos a distância é perceptível em função da valorização do processo e não do produto. Ou seja, o contato necessário entre aluno e professor favorece a este conhecer o aluno e conseqüentemente a estranhar mudanças abruptas de comportamento cognitivo.

Entretanto, para quem julga essa dificuldade como limitante da EaD, engana-se a partir do que foi expresso por Ro, uma vez que, essa participante argumenta sobre a dificuldade em saber "quem" faz a prova, estar vinculada também à modalidade presencial. Tal fato permite ao participante Fer que retome seu conceito a respeito da similaridade semântica que estava dando aos termos "prova" e "avaliação", fato visto quando esse manifesta concordar com Ro. Nesse sentido, garantimos a depuração compartilhada que privilegia a formação de cada um dos envolvidos e que, nesse caso, nos permite, da mesma forma, avaliá-los formativamente.

Logo, o processo avaliativo formativo, o qual é tomado como aspecto teórico levantado nesse artigo, vincula-se ao Construcionismo, uma vez que esse último, biunivocamente, também se insere na perspectiva formativa a partir de ações de aprendizagem que favorecem a construção do conhecimento (VALENTE, 1993, 1999, 2002; MALTEMPI, 2000, 2004; ROSA, 2004).

\section{Considerações finais}

Analisamos, nesse artigo, episódios que são fragmentos de um dos encontros síncronos que realizamos no curso citado. Cabe 
salientar que discutimos apenas uma fração de todos os dados que obtivemos (fato que faz parte do próprio processo avaliativo) e, nesse sentido, cabe também lembrar que toda a discussão foi gerada e mantida pela construção de RPGs Eletrônicos Educativos (produto que foi desenvolvido no decorrer do curso, por cada um dos participantes), mesmo que esses não sejam o centro do processo avaliativo.

A partir dessa perspectiva, a construção de RPGs eletrônicos a distância carrega consigo, entre outros aspectos, a possibilidade de se exercer a avaliação formativa vinculada ao Construcionismo. Podemos, então, formalizar tal faceta como uma das características da EaD. Essa possibilidade contribui muito para que haja a construção do conhecimento, que toma as ações de aprendizagem vistas no Turbilhão de Aprendizagem (ROSA, 2004) como critérios de sustentação à formação.

Isso nos permite dizer que a EaD começa a apresentar elementos que a caracteri- zam. Ou seja, a avaliação formativa sob um aspecto construcionista revela-se, então, como um das facetas dessa modalidade de ensino e aprendizagem. Assim, embora possamos importar evidências da EaD como as relacionadas ao tempo e espaço, percebemos que as limitações identificadas com determinados conteúdos, por exemplo a Matemática, podem ser amenizadas por características possíveis de serem executadas na própria EaD, como a avaliação formativa, na qual há a valorização do processo em relação ao produto e cuja concepção desvincula-se do quantificar saberes e relaciona-se ao formar sujeitos.

A EaD, então, possui aspectos que podem favorecer a prática educativa. Entre eles, a avaliação como processo formativo pode ser vista a partir da constituição de um cenário que se utiliza da construção de RPGs eletrônicos como elemento fundamental e, assim, potencializar os fatores que corroboram a defesa da construção do conhecimento em práticas pedagógicas. 


\section{Referências}

BALDASSIN, A. J.; GUILHERME, I. R.; MALTEMPI, M. V. Uma abordagem baseada em agentes para filtragem de correspondências eletrônicas. Revista Eletrônica de Iniciação Científica (REIC): revista da Sociedade Brasileira de Computação, Porto Alegre, v. 2, n. 4, 2002. Disponível em <http://www.sbc.org.br/reic/edicoes/ 2002e4>. Acesso em: outubro de 2005.

BORBA, M. C. Dimensões da educação matemática a distância. In: BICUDO, M. V.; BORBA, M. C. (Org.). Educação matemática: pesquisa em movimento. São Paulo: Cortez, 2004.

BORBA, M. C.; PENTEADO, M. G. Informática e educação matemática. Belo Horizonte: Autêntica, 2001.

D’AMBRÓSIO, U. Educação matemática: da teoria à prática. 10. ed. Campinas, SP: Papirus, 2003.

HOFFMANN, J. M. L. Avaliação: mito e desafio: uma perspectiva construtivista. 20. ed. Porto Alegre: Mediação, 1996.

JAQUES, P.; ANDRADE, A.; JUNG, J.; BORDINI, R.; VICARI, R. Using pedagogical agents to support collaborative distance learning. In: COMPUTER SUPPORT COLLABORATIVE LEARNING, 2002, Boulder. Proceedings... New Jersey: LEA, 2002. p.546-557.

KENSKI, V. M. Tecnologias e ensino presencial e a distância. Campinas, SP: Papirus, 2003.

MAES, P. Agents that reduce work and Information overload. Communications of the ACM, New York, v. 37, n. 7, p. 31-41, July 1994.

MALTEMPI, M.V. Construção de páginas Web: depuração e especificação de um ambiente de aprendizagem. 2000. Tese (Doutorado)-Faculdade de Engenharia Elétrica e de Computação, Universidade Estadual de Campinas, Campinas, SP, 2000.

Construcionismo: pano de fundo para pesquisas em informática aplicada à educação matemática. In: BICUDO, M. A. V.; BORBA, M. C. (Org.). Educação matemática: pesquisa em movimento. São Paulo: Cortez, 2004.

. Novas tecnologias e construção de conhecimento: reflexões e perspectivas. In: CONGRESSO IBERO-AMERICANO DE EDUCAÇÃO MATEMÁTICA, 2005, Porto. Anais... Porto, PT, 2005. 
MARTINS, M. C. Criança e mídia: "diversa-mente" em ação em contextos educacionais. Tese (Doutorado em Multimeios)-Universidade Estadual de Campinas, Campinas, SP, 2003.

MIZUKAMI, M. G. N. Ensino: as abordagens do processo. São Paulo: EPU, 1986.

OLIVEIRA, L. M. P. Educação a distância: novas perspectivas a formação de educadores. In: MORAES, M. C. (Org.). Educação a distância: fundamentos e práticas. Campinas, SP: UNICAMP, NIED, 2002.

PERRENOUD, P. Avaliação: da excelência à regulação das aprendizagens. Porto Alegre, RS: Artes Médicas, 1999.

PRIBERAM. Dicionário universal da língua portuguesa. Lisboa, PT: Priberam Informática, c1999. Disponível em:<http://www.priberam.pt/dlpo>. Acesso em: 19 set. 2005.

ROCHA, H. V. O ambiente TelEduc para educação a distância baseada na Web: princípios, funcionalidades e perspectivas de desenvolvimento. In: MORAES, M. C. (Org.). Educação a distância: fundamentos e práticas. Campinas, SP: UNICAMP, NIED, 2002.

ROSA, M. Educação matemática e Role Playing Game: masmorras e dragões. São Paulo: Devir Editora, 2005. No prelo.

Role Playing Game eletrônico: uma tecnologia lúdica para aprender e ensinar matemática. 2004. Dissertação (Mestrado em Educação Matemática)-UNESP, Rio Claro, SP, 2004.

RUSSEL, S.; NORVIG, P. Artificial intelligence: a modern approach. New Jersey: PrenticeHall, 1995.

VALENTE, J. A. Análise dos diferentes tipos de softwares usados na educação. In: VALENTE, J. A. (Org.). O computador na sociedade do conhecimento. Campinas, SP: Gráfica da UNICAMP, 1999.

A espiral da aprendizagem e as tecnologias da informação e comunicação:

repensando conceitos. In: JOLY, M. C. R. A. (Org.). A tecnologia no ensino: implicações para a aprendizagem. São Paulo: Casa do Psicólogo, 2002.

Por quê o computador na educação?. In: VALENTE, J. A. (Org.). Computadores e conhecimento: repensando a educação. Campinas, SP: UNICAMP, NIED, 1993.

Recebido em: 03/01/2006

Aceito para publicação em: 21/01/2006 
O arquivo disponível sofreu correções conforme ERRATA publicada no Volume 14 Número 51 da revista. 